\title{
Research On the Application of Static Var Compensator in Fushun Power Grid
}

\author{
Yujie Pei1, Liang Cao2, Qingyan Meng1, Guang Tong1, Yaoding \\ Gu1, Yubin Dong1, Wenjing Mu2 \\ 1Fushun Power Supply Company, Liaoning Electric Power Company \\ Limited, State Grid, Fushun, 113008, China \\ 2Rongxin Power Electronic Co., Ltd., Anshan, Liaoning 114051, China
}

\begin{abstract}
in recent two years, electrical load in Fushun District increases continuously, and the impact and harmonic pollution on the power grid rises continuously, voltage quality problem becomes aggravated. Through multi-disciplinary analysis and demonstration, Fushun Power Supply Company installed SVC/SVG in 220kV load center substation and $66 \mathrm{kV}$ terminal substation in 2010 and 2011 respectively to regulate reactive power of the system for the purpose of stabilized voltage and less line loss. This paper introduces actual operation situation of these two sets of SVC/SVG in the substations, and provides helpful reference for similar applications in the future by conducting effectiveness analysis and summarizing experiences and lessons.

Keywords: $66 \mathrm{kV}$ directly connected SVC, chain SVG, line loss rate

\section{Introduction}

Fushun is always a heavy industry city in Liaoning District with numerous metallurgy and petrochemical enterprises. In recent years, several new economic development zones and residential areas have been built in the suburb of Fushun City and peripheral rural areas. The inrush of a large number of enterprises and residents activates the conflict between electrical load and power supply capability. For example, Fushun Lishizhai $220 \mathrm{kV}$ Substation, although its $220 \mathrm{kV}$ bus voltage is in reasonable scope, $66 \mathrm{kV}$ bus voltage fluctuates greatly (see Fig.1) and both long-term flicker and short-term flicker are overproof caused by the load at lower-level.
\end{abstract}




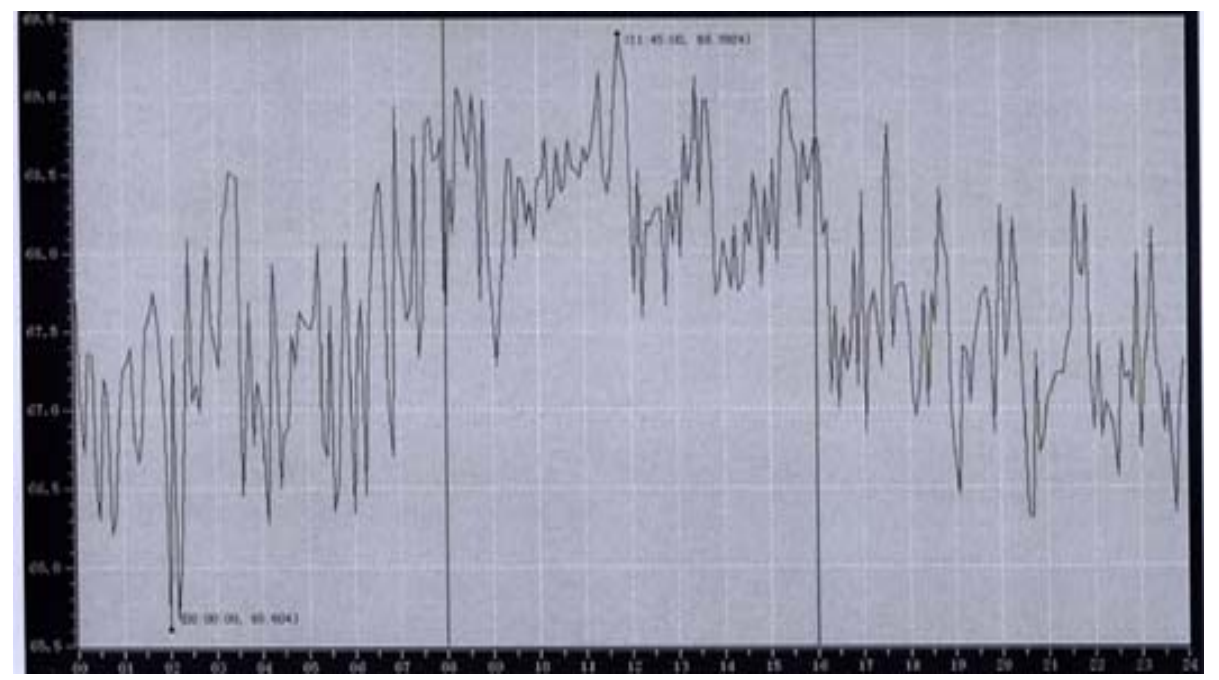

Fig. 1 Bus Voltage Curve of Lishizhai Substation 66kV (before SVC was put into operation)

Table 1, Power Quality Indexes of Lishizhai Substation $66 \mathrm{kV}$ Bus

\begin{tabular}{|c|c|c|c|c|c|}
\hline \multicolumn{2}{|c|}{ Parameters } & $\begin{array}{c}\text { Max. } \\
\text { value }\end{array}$ & $\begin{array}{c}\text { Min. } \\
\text { value }\end{array}$ & $\begin{array}{c}95 \% \\
\text { value }\end{array}$ & $\begin{array}{c}\text { International } \\
\text { value }\end{array}$ \\
\hline \multicolumn{2}{|c|}{$\begin{array}{c}\text { Three-phase voltage } \\
\text { unbalance (\%) }\end{array}$} & 0.73 & 0.06 & 0.48 & 2.00 \\
\hline \multirow{2}{*}{$\begin{array}{c}\text { Short-term } \\
\text { flicker (1) }\end{array}$} & Phase A & 2.62 & 0.30 & 2.10 & 0.80 \\
\cline { 2 - 6 } & Phase B & 2.38 & 0.29 & 1.96 & 0.80 \\
\cline { 2 - 6 } & Phase C & 2.46 & 0.24 & 2.04 & 0.80 \\
\hline \multirow{2}{*}{$\begin{array}{l}\text { Long-term } \\
\text { flicker (1) }\end{array}$} & Phase A & 1.58 & 1.01 & 1.58 & 0.60 \\
\cline { 2 - 6 } & Phase B & 1.49 & 1.01 & 1.49 & 0.60 \\
\cline { 2 - 6 } & Phase C & 1.59 & 0.91 & 1.59 & 0.60 \\
\hline \multirow{2}{*}{$\begin{array}{c}\text { Harmonic voltage distortion } \\
\text { factor (\%) }\end{array}$} & 1.15 & 0.34 & 0.85 & 3.0 \\
\hline
\end{tabular}

Voltage of $66 \mathrm{kV}$ and $10 \mathrm{kV}$ buses in lower-level $66 \mathrm{kV}$ substations (such as Maoyan Substation etc) of Lishizhai $220 \mathrm{kV}$ Substation is affected with high fluctuation, below lower limit and high line loss. 


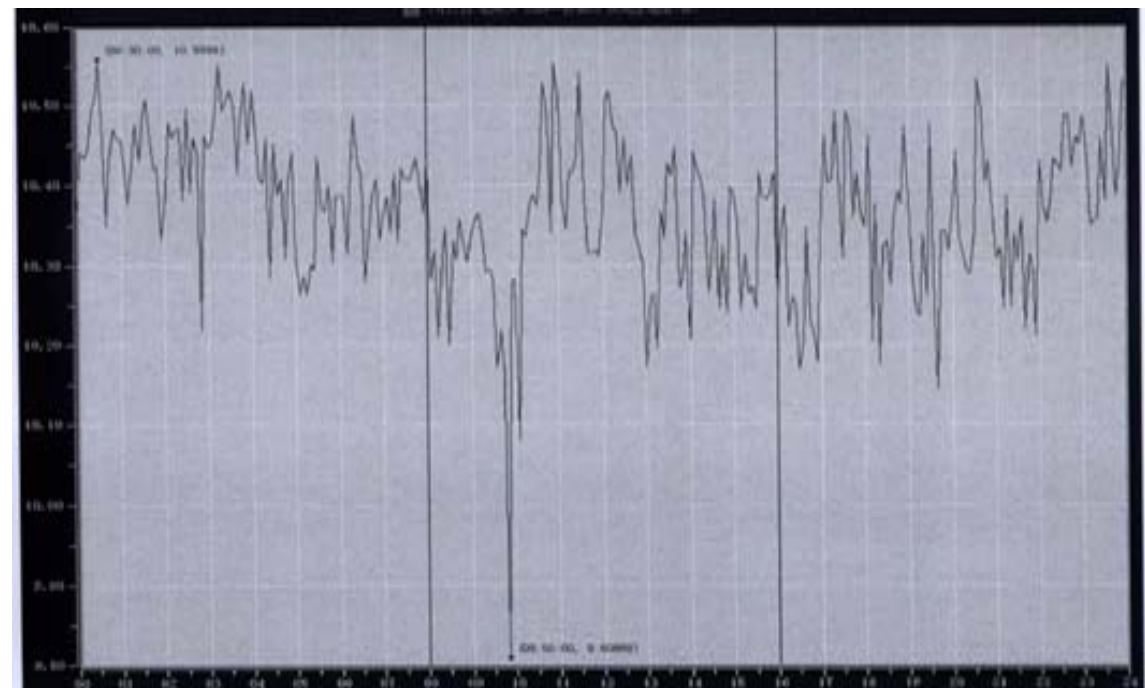

Fig. $210 \mathrm{kV}$ Bus Voltage Curve of Maoyan (before SVC was put into operation)

In Fushun Power Grid, some substations also have similar voltage quality problem due to their location on the terminals of power supply line. For example, with respect to $66 \mathrm{kV}$ Qingyuan Substation on the terminal of $220 \mathrm{kV}$ Zhongqing Line 1, voltage of $10 \mathrm{kV}$ bus is low, and line loss is high. See Fig.2.

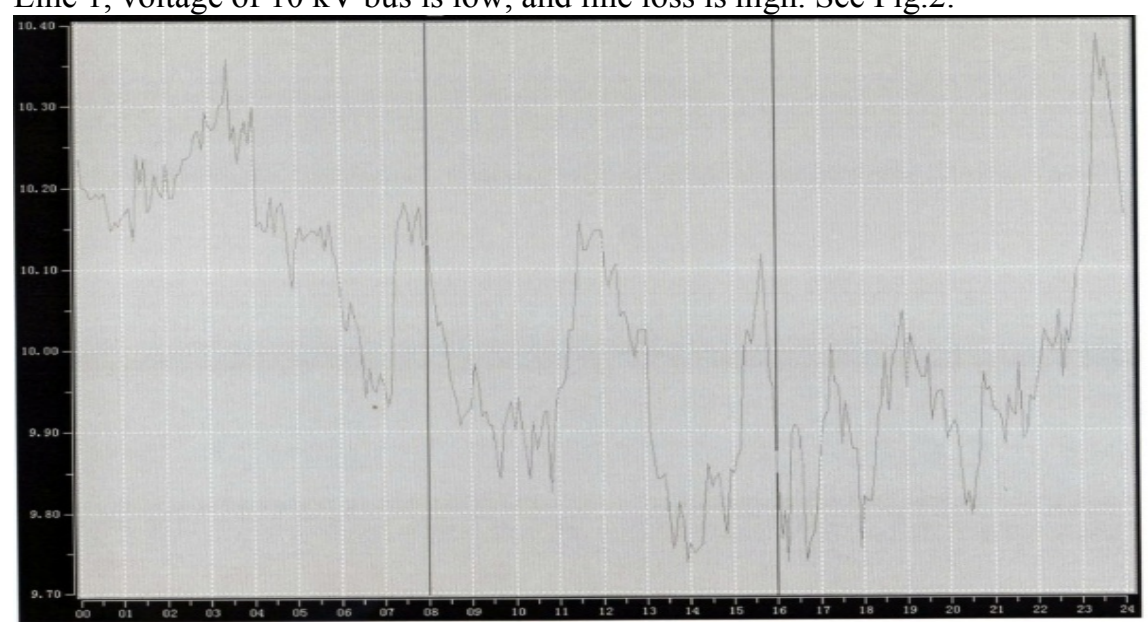

Fig. 3 Voltage Curve of $10 \mathrm{kV}$ Section I Bus at Qingyuan Substation (before SVG was put into operation)

To sum up, voltage quality problem of $66 \mathrm{kV}$ Maoyan Substation is mainly caused by $220 \mathrm{kV}$ Substation at the next higher level, while voltage quality problem of $66 \mathrm{kV}$ Qingyuan Substation is caused by its geographic location. Although the reasons are different, power consumption quality of the users is affected, and line loss is high, which all should be solved.

Through comprehensive investigation of $220 \mathrm{kV}$ Lishizhai Substation, $66 \mathrm{kV}$ Maoyan Substation and $66 \mathrm{kV}$ Qingyuan Substation, as well as domestic 
manufacturing capacity of dynamic reactive power compensation equipment, a scheme is finally formulated to install $66 \mathrm{kV}$ directly connected SVC(compensating capacity $70 \mathrm{M}$ ) at Lishizhai Substation and 10kV chain SVG (compensating capacity $\pm 5 \mathrm{M}$ ) at Qingyuan Substation for compensation purpose.

Application of $66 \mathrm{kV}$ directly connected SVC at Lishizhai Substation

Basic parameters of this SVC are as follows: rated capacity 70MVar, rated voltage $66 \mathrm{kV}$, rated current $371 \mathrm{~A}$; valve block trigger mode: light triggered; installed capacity of filter: 98MVar(fundamental wave compensating capacity: 70MVar); filter branch: 3rd, 5th, 7th; cooling system: closed circulating pure water cooling device; land area: $85 \mathrm{~m} * 25 \mathrm{~m}$; installation site: Lishizhai Substation $66 \mathrm{kV}$ bus; control strategy: constant voltage control.

Before SVC was put into operation, voltage fluctuation range of Lishizhai $66 \mathrm{kV}$ bus was 65.60 to $69.39 \mathrm{kV}$ while 67.31 to $68.01 \mathrm{kV}$ after putting into operation.

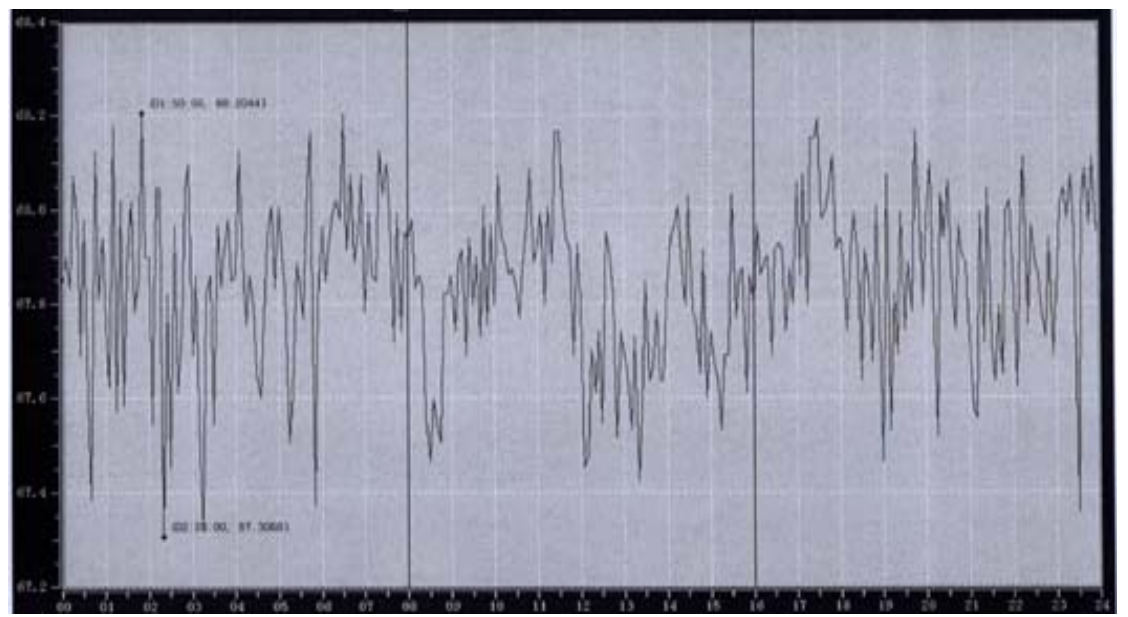

Fig. 4 Voltage Curve of 66kV Bus at Lishizhai Substation (after SVC was put into operation)

In addition, voltage fluctuation range of $10 \mathrm{kV}$ bus at its affiliated Maoyan Substation changed from $9.81-10.56 \mathrm{kV}$ to $10.35-10.67 \mathrm{kV}$. 


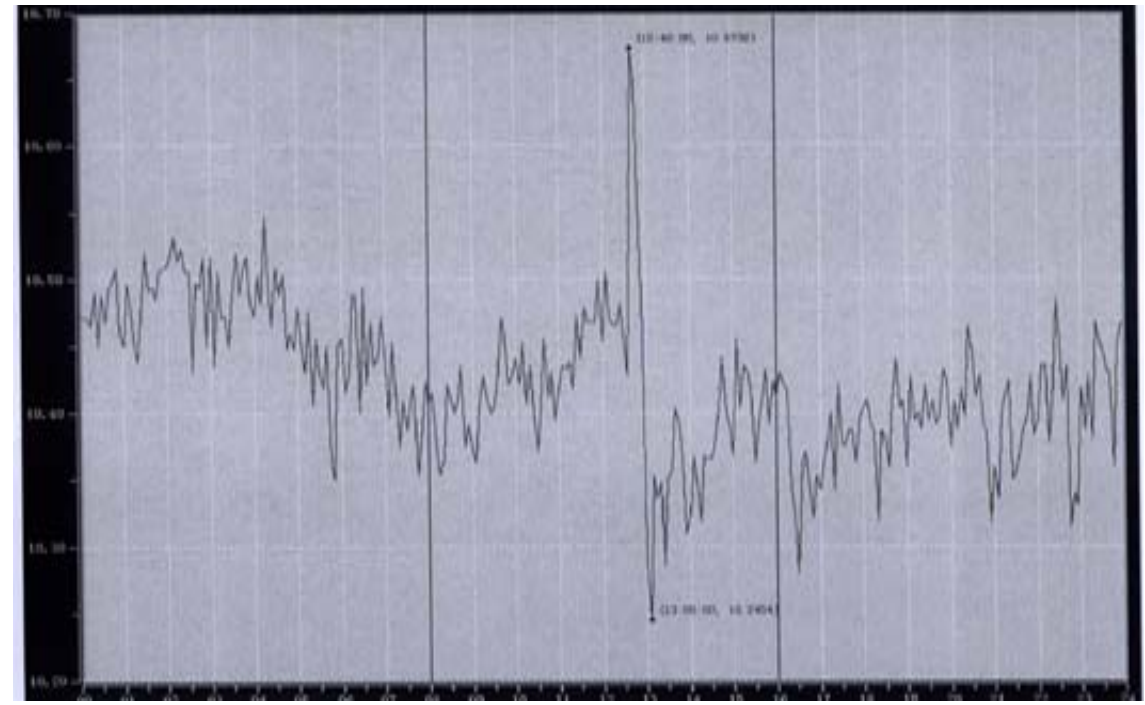

Fig. 5 Voltage Curve of $10 \mathrm{kV}$ Bus at 5 Maoyan Substation (after SVC was put into operation)

Application of SVG at Qingyuan Substation

Basic parameters of this SVG: rated capacity $\pm 5 \mathrm{MVar}$, rated voltage $10.5 \mathrm{kV}$, rated current 289A; cooling system: air cooling; land area: $9.6 \mathrm{~m} * 12 \mathrm{~m}$; installation site: Qingyuan Substation Section I $10 \mathrm{kV}$ bus; control strategy: constant voltage control.

Before SVG was put into operation, voltage fluctuation range of $10 \mathrm{kV}$ bus at Qingyuan Substation was $9.8-10.3 \mathrm{kV}$ while $10.3-10.7 \mathrm{kV}$ after putting into operation. 


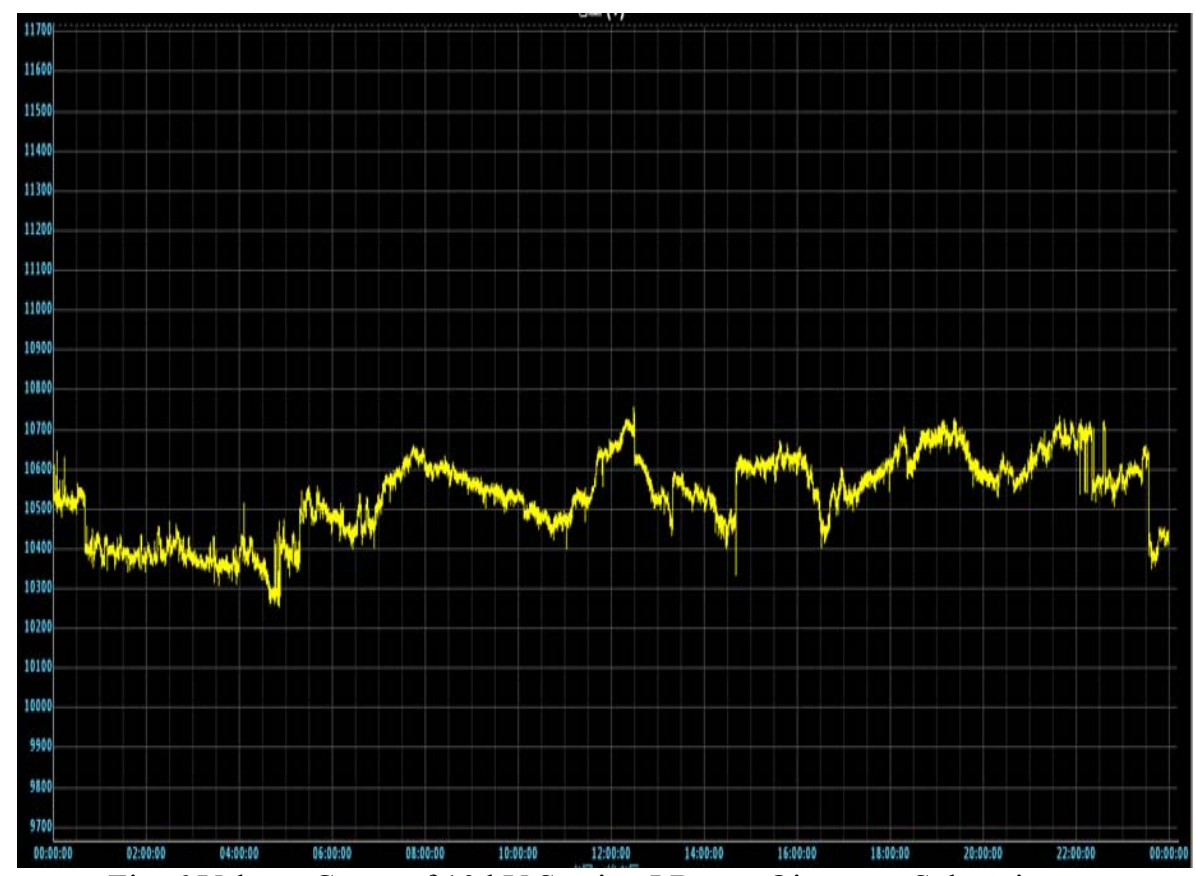

Fig. 6 Voltage Curve of $10 \mathrm{kV}$ Section I Bus at Qingyuan Substation (after SVG was put into operation)

\section{Economic Benefits Analysis After SVC was Put into Operation}

(1) Analysis on transmission loss of $220 \mathrm{kV}$ and above

After SVC was installed, subsequent reduction of primary transmission loss is calculated as per $1.97 \mathrm{MW}$ and annual operation time as per $8700 \mathrm{~h}$, the reduced primary transmission loss of Liaoning Power Grid in one year: $1.97(\mathrm{MW}) \times 8700$ (hour) $=17.139$ million $(\mathrm{kWh})$.

(2) Analysis on transmission loss below $220 \mathrm{kV}$

The power loss of two main transformers at Lishizhai Substation in 2009 was 5.93 million $\mathrm{kWh}$, and according to the power supply quantity of Lishizhai Substation about 598.90 million $\mathrm{kWh}$ in 2009 , total power loss about 7.60 million $\mathrm{kWh}$. After SVC was installed, $66 \mathrm{kV}$ system voltage became $68 \mathrm{kV}$, secondary transmission loss of the system could reduce power loss 2.17 million $\mathrm{kWh}$.

(3) Annual power consumption of SVC

It is estimated that comprehensive loss of SVC (including various auxiliary equipments, station-service power and power penetrating main transformer loss etc) is $0.3 \%$, total consumed active electricity is calculated as 2.349 million $\mathrm{kWh}$

Then after SVC was put into operation, the reduced power loss is 1713.9+217-234.9=16.96 million kWh

Calculate as per 0.5 Yuan per $\mathrm{kWh}$, annual income is 8.48 million Yuan. 


\section{Economic Benefits Analysis after SVG was Put into Operation}

After SVG was put into operation, average power transmission and transformation loss rate of Zhongqing Line 1 decreases $1.01 \%$, compared with that before SVG was put into operation

Direct economic benefits of line loss $=$ annual sold electricity $*$ reduced line loss rate $*$ average unit price of electricity sold $=219$ million $\mathrm{kWh} * 1.01 \% * 5950$ Yuan/ten thousand $\mathrm{kWh}=1.316$ million Yuan

Daily average power supply quantity of Qingyuan Substation increases from original $93101 \mathrm{~kW} \cdot \mathrm{h}$ to current $101814 \mathrm{~kW} \cdot \mathrm{h}$, growth rate is $9.35 \%$. Benefits of additional electricity sold $=$ annual quantity of additional electricity sold $*$ profit of electricity price $=3.18$ million $\mathrm{kWh} \times(5950-3672)$ Yuan/ten thousand $\mathrm{kWh}$ $=0.724$ million Yuan

Annual comprehensive economic benefits after SVG was put into operation = benefits of additional electricity sold + direct economic benefits of line loss $=2.0404$ million Yuan.

\section{Conclusion}

Facts have proved that, both the SVC at $220 \mathrm{kV}$ Lishizhai Substation and the SVG at Qingyuan Substation have solved the problems of local grid, i.e. large voltage fluctuation, low voltage and high line loss effectively, and achieved relatively high economic benefits and social benefits. Through contrast analysis, the advantage of the installation at $220 \mathrm{kV}$ Substation is wide compensation coverage and the disadvantage is large footprint, which might impact the system to certain degree; for the installation at $66 \mathrm{kV}$ Substation, advantages include god compensation effect and strong pertinency, and the disadvantage is heavy investment. In addition, since $66 \mathrm{kV}$ directly connected SVC adopts water cooling method, regular maintenance is required for the water cooling system, while SVG also requires regular cleaning of the air cooling system, so maintenance workload of operating and maintenance personnel is increased.

\section{References}

[1] Luo Chenglian "Principle and Realization of Static Reactive Synchronous Compensator (STATCOM)" [M]. Beijing: China Electric Power Press, 2005;

[2] An Wanzhu, Wang Jian, Wang Xiaoyan, Wang Zhiming, Ge Weichun, Gong Hengyu. Double Redundancy Control System of $66 \mathrm{kV}$ Vertical SVC [J]. Electric Age. 2010(2):48-51.

[3] Liu Wenhua,Song Qiang,Teng Tianle,et al.Transient Voltage stability and static synchronous compensator [J]. Transactions of China Electrotechnical Society,2007,2(7):18-23. 
[4] Weng Limin,Xin Jianfeng.Performance comparison and application analysis between STATCOM and SVC [J]. Power Capacitor \&Reactive Power Compensation,2010,31(4):1-4. 